\title{
Mitigating Heat Islands Effect in Mega Cities through Districts' Prioritisation for Urban Green Coverage Applications: Cairo - Egypt as a Case Study
}

\author{
Mohsen Aboulnaga ${ }^{1, *}$ and Mona Mostafa ${ }^{2}$ \\ ${ }^{1}$ Sustainable Built Environment, Department of Architecture, Faculty of Engineering, Cairo University, Cairo, Egypt \\ 2 Environment \& Energy Efficiency Master Programme, Department of Architecture, Cairo University, Cairo, Egypt
}

Accepted: 7 January 2019

\begin{abstract}
Heat-related problems have become a global issue resulted from climate change. Prolonged exposure to extreme high temperatures increased the percentage of mortality and morbidity in cities worldwide. Urbanization and population contribute to urban heat islands effect (UHIE). The purpose of this paper is to prioritize urban areas at high risk for heat related incidents in mega cities and to propose the implementation of urban green coverage (UGC) strategies which contribute to mitigating UHIE. The methodology includes a review on the UHI problems, along with the cooling benefits the UGC can produce. Then, the study's application is mainly focused on Cairo Governorate, Egypt as an example of a developing country. Cairo Governorate, Egypt lacks well maintained vegetation in almost all districts as results indicated that it has a mean normalized difference vegetation index (NDVI) ranging from 0.08 to 0.25 . The study adopts the Australian model developed by Norton et al. [Landsc. Urban Plan. 134, 127 (2015)], which includes the intersection of three factors (heat exposure, vulnerability, and behavioural exposure) to identify a high priority area. It was difficult to assess the behaviour of population in outdoor public spaces in a city like Cairo; hence, the study follows "Crichton's Risk Triangle" conducted by Morabito et al. [PLoS One 10, e0127277 (2015)], to identify high risk areas based on the intersection of three layers: (a) high day-time/night-time surface temperatures - hazard; (b) total exposed population in a city - exposure; and (c) sub-populations at risk of being harmed during extreme heat vulnerability. In the simulation, the risk assessment method simplifies the process of constructing the GIS database as it is composed of layering system. The development of a Heat-related Vulnerability Index (HVI) map for Cairo districts was conducted by over layering the natural hazard layer (land surface temperature) with spatial demographic data using GIS Software. Results of risk maps of Cairo were presented and showed normalized HVI values ranging between 0.0 and 1.0, which can be categorized into five risk levels (very low to very high). Results also indicated that 13 out of the 46 districts in Cairo are at very high/high risk, while only 5 districts have a very low risk. Finally, a tool was established to map the population vulnerability to extreme heat events by identifying high priority risk areas that requires urgent intervention by applying more UGC to mitigate UHIE and climate action and adaptation.
\end{abstract}

\section{Introduction}

Heat-related problems have become a global concern due to severe events caused by climate change. Adaptation to climate change has proven significant mean to mitigate such risks, especially in urban areas. The presence of vegetation is significant in urban spaces as it plays a role in enhancing the environmental conditions by shading heat

\footnotetext{
* e-mail: mohsen_aboulnaga@yahoo.com
}

absorbing surfaces, providing evaporative cooling and altering wind patterns [1,2]. Due to the fast urban development, natural surfaces and vegetation are replaced in some cities by materials with characteristics such as: high thermal conductivity, high heat absorption, and heat storage capacity as well as low albedo values (reflectivity) that result in absorbing solar radiation during the day and releasing it at night as sensible heat. Thus, urban areas in cities become warmer than the surrounding countryside; a phenomenon known as Urban Heat Island Effect (UHIE) [3]. The scientific term of "UHIE" became well known in 

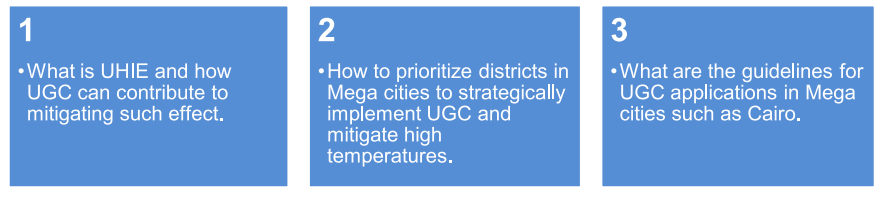

Fig. 1. Sub-assumptions of the study.

1820 by Luke Howard when compared two rows of air temperature data measured inside and outside the city, and reported in 1800 that in London, night temperature is warmer in the city than in country $[4,5]$.

\section{Objectives}

The goal of this study is to prioritise districts in urban areas in developing countries for implementing urban green coverage (UGC) as a method for mitigating high temperatures' impact and contribute to reducing UHIE in these urban areas. It also provides landscape architects and urban designers with the findings to strategically fit UGC that ameliorate the negative effects of UHI in the context of global climate change in cities. The main research assumption is what are the most areas that urgently require UGC implementation in Cairo? This study will also provide answers to the sub-assumption shown in Figure 1.

\section{Cities' challenges and urban heat island problems}

\subsection{Urban heat island effect and urban green coverage in Egypt}

UHIE refers to a climatic phenomenon expressed when urban areas have higher air temperature than their rural surroundings due to the anthropogenic modifications of land surfaces [6,7]. However, due to the urban growth, no distinct borderlines exists between urban and rural areas, thus UHIE can be described in terms of the difference in temperature between the central parts of the city and its surrounding areas [7].

In mega cities such as Cairo, Egypt, the magnitude of UHIE ranged from $3.11^{\circ} \mathrm{C}$ to $5.7^{\circ} \mathrm{C}$ [8]. In summer 2012, land surface temperature (LST) varied from $27^{\circ} \mathrm{C}$ to $61^{\circ} \mathrm{C}$ [7]. The UHI intensity index in Cairo has five dominant levels, with least intensity in vegetated areas/water bodies, while highest in scattered bare land areas and industrial zones [9]. Thus, the above observations make it a necessity to develop means to determine the hot spots in Cairo Governorate, to prioritize and propose strategies for high temperatures mitigation. In addition, the study proposes UGC as a method to reduce UHIE [8]. In Egypt, urban areas have expanded on the account of green areas [10]. According to international standards, areas of green spaces should range from $20 \mathrm{~m}^{2}$ to $40 \mathrm{~m}^{2}$ per person in developed countries, while it should be $12 \mathrm{~m}^{2}-18 \mathrm{~m}^{2}$ per person in developing countries [11,12]. Nonetheless, most optimistic studies state that the green space per person in Cairo does not exceed $2.0 \mathrm{~m}^{2}$. Such area is considered very low when

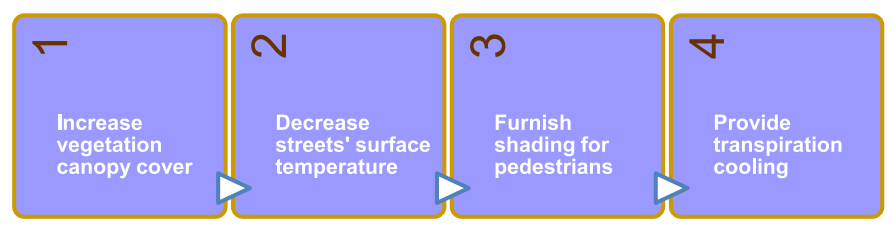

Fig. 2. Goals of good selection of urban green coverage. Source: [13].

compared to international norms, where more than half of Cairo's population have only $0.5 \mathrm{~m}^{2}$ per person. Moreover, about million person in Cairo have green per capita ratio less than $0.1 \mathrm{~m}^{2}$ per person since green areas are not distributed in spatial justice in Cairo city [12].

\subsection{Cooling effect of urban green coverage (UGC)}

UGC refers to the use of strategies such as: green open spaces, trees, green roofs, and vertical walls. The presence of green coverage in a city can be assessed by the normalized difference vegetation index (NDVI), which is a graphical indicator used to analyse satellite images to determine whether if the selected location has well maintained green vegetation or not [8]. It is important to choose the UGC that fits the place it will be implemented in. The ultimate goals of this step are illustrated in Figure 2. In cities around the globe, UGC in urban areas can take many forms apart from conventional green urban spaces, such as vertical farming, green walls, and green walls as illustrated in Figure 3. It is crucial to understand how to locate different elements of the UGC in places that would maximize their surfaces' cooling benefits. Table 1 highlights the strategic use of different UGC.

\section{Methodology}

In this study, the methodology adopted is based on a theoretical and a practical approach to investigate the prioritisation of districts on city scale level according to the Australian model developed by Norton et al. [13]. This suggests that the impact of UHIE is centred on a combination of many factors including heat exposure, vulnerability to extreme heat, and the behavioural exposure occurring (Fig. 4a). Thus, a high priority area can be identified by the intersection of three factors as mentioned below:

(1) High day-time/night-time surface temperatures (heat exposure).

(2) Most vulnerable sections of the society to extreme heat (vulnerability).

(3) Zones with many users active outdoor (behavioural exposure).

It is vital to highlight that areas where heat exposure and vulnerability intersect (area B) are also considered a priority, as it is strenuously demanding to predict the amount of behavioural exposure in public open spaces [13]. In Cairo city, it was difficult to assess the behaviour of 

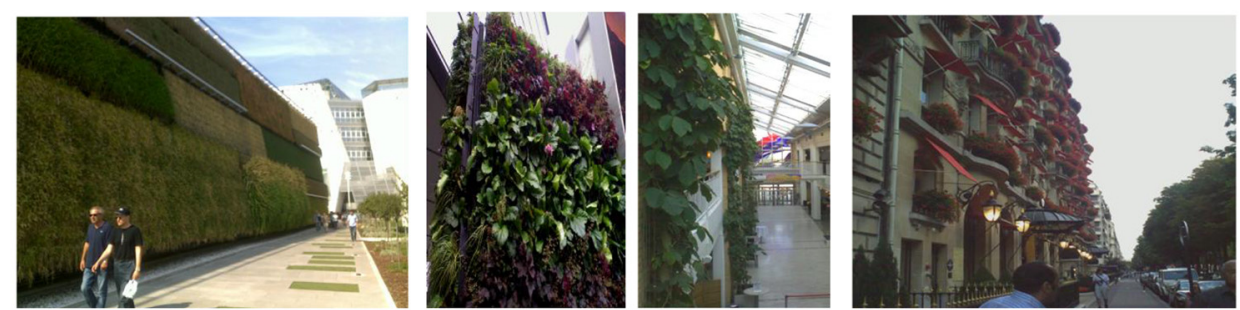

a. Green wall, Milan Expo'16, Milan b. Green walls, London\& Bucharest
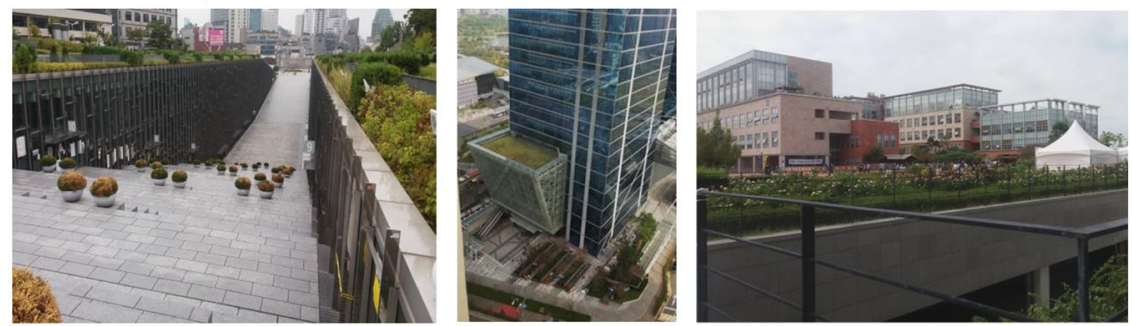

d. Green roof, EWHA University, Seoul e. Green roof, Incheon f. Green roof, INU, Songdo-Incheon, SK

Fig. 3. Various innovative set up of urban green coverage. Photo credits: (Authors 2010, 2015, 2016).

Table 1. Strategic use of different urban green coverage (UGC).

\begin{tabular}{|c|c|c|c|c|}
\hline UGC & Green open spaces & Trees & Green roofs & Vertical greening \\
\hline $\begin{array}{l}\text { Shades canyon } \\
\text { surfaces? }\end{array}$ & $\begin{array}{l}\text { Yes, if grass rather } \\
\text { than concrete }\end{array}$ & Yes & $\begin{array}{l}\text { Shades roof, not internal } \\
\text { canyon surfaces }\end{array}$ & Yes \\
\hline Shades people? & Yes, if treed & Yes & $\begin{array}{l}\text { No, only very intensive } \\
\text { green roofs }\end{array}$ & No \\
\hline $\begin{array}{l}\text { Increases solar } \\
\text { reflectivity? }\end{array}$ & Yes, when grassed & Yes & Yes, if plants healthy & Yes \\
\hline $\begin{array}{l}\text { Evaporative } \\
\text { cooling? }\end{array}$ & Yes, with water & $\begin{array}{l}\text { Yes } \\
\text { (Unless severe drought) }\end{array}$ & Yes, with water when hot & $\begin{array}{l}\text { Yes, with water } \\
\text { when hot }\end{array}$ \\
\hline \multirow{4}{*}{$\begin{array}{l}\text { Priority } \\
\text { locations }\end{array}$} & No, without water & & No, without water & No, without water \\
\hline & $\begin{array}{l}\text { - Wide streets with } \\
\text { low buildings } \\
\text { - both sides }\end{array}$ & $\begin{array}{l}\text { - Wide streets, low buildings } \\
\text { - both sides }\end{array}$ & - Sun exposed roofs & $\begin{array}{l}\text { - Canyon walls with } \\
\text { direct sunlight }\end{array}$ \\
\hline & \multirow[t]{2}{*}{$\begin{array}{l}\text { - Wide streets with } \\
\text { tall buildings } \\
\text { - sunny side }\end{array}$} & $\begin{array}{l}\text { - Wide streets, } \\
\text { tall buildings - sunny side }\end{array}$ & - Poor insulated buildings & \multirow[t]{2}{*}{$\begin{array}{l}\text { - Narrow or wide } \\
\text { canyons where } \\
\text { trees are unviable }\end{array}$} \\
\hline & & - Green open spaces & $\begin{array}{l}\text { - Low, large buildings } \\
\text { - Dense areas with little } \\
\text { available ground space }\end{array}$ & \\
\hline
\end{tabular}

Source: [13].

population in outdoor public spaces; therefore, the study follows "Crichton's Risk Triangle", as conducted by Morabito et al. [14], to identify high risk areas based on the intersection of three layers (Fig. 4b). The three components of this triangle are: (1) high day-time/nighttime surface temperatures (hazard); (2) total exposed population in a city (exposure); and (3) sub-populations at risk of being harmed during extreme heat (vulnerability). It is necessary to develop methods to assess the influencing parameters. Firstly, concerning the heat exposure, LST for an area provided from satellite or airborne remotely sensed thermal data can be used as an indication for air

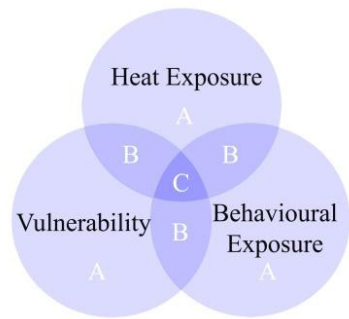

a. Method of A. Norton et al.

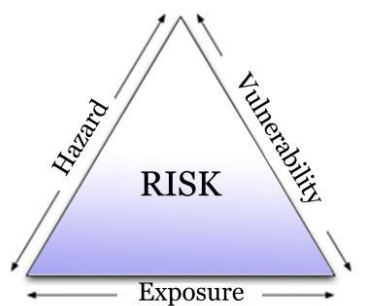

b. Crichton's Risk Triangle
Fig. 4. Mapping the relationship between variables that affect the prioritisation of areas. 
Table 2. Description of the data used in the study.

\begin{tabular}{|c|c|c|c|}
\hline Data used & Data description & Year & Data source \\
\hline $\begin{array}{l}\text { Cairo districts } \\
\text { boundaries }\end{array}$ & $\begin{array}{l}\text { Cairo districts geographical } \\
\text { boundaries layer in ARC map }\end{array}$ & 2017 & $\begin{array}{l}\text { Digitized by author } \\
\text { based on http://www.cairo.gov.eg/ }\end{array}$ \\
\hline $\begin{array}{l}\text { Day-time land surface } \\
\text { temperature (LST) }\end{array}$ & $\begin{array}{l}\text { Raster image of day-time } \\
\text { LST covering the study area }\end{array}$ & $\begin{array}{l}(18.06 .2017 \text { to } \\
25.06 .2017)\end{array}$ & $\begin{array}{l}\text { NASA Satellite remote } \\
\text { sensing MODIS (MOD11A2) } \\
\text { consisting of LST at } 8 \text { days } \\
\text { temporal and Global } 1.00 \mathrm{~km} \\
\text { spatial resolution Grid V006 } \\
\text { both for day-time and night-time } \\
\text { conditions during the period. } \\
\text { (https://search.earthdata.nasa.gov) }\end{array}$ \\
\hline Night-time LST & $\begin{array}{l}\text { Raster image of night-time } \\
\text { LST covering the study area }\end{array}$ & & \\
\hline $\begin{array}{l}\text { Normalized } \\
\text { difference vegetation } \\
\text { index (NDVI) }\end{array}$ & $\begin{array}{l}\text { Raster image of LST } \\
\text { covering the study area }\end{array}$ & $\begin{array}{l}(1.06 .2017 \text { to } \\
30.06 .2017)\end{array}$ & $\begin{array}{l}\text { NASA Satellite remote } \\
\text { sensing MODIS (MOD13A3) } \\
\text { for NDVI data provided } \\
\text { monthly at 1-km spatial resolution. } \\
\text { (https://search.earthdata.nasa.gov) }\end{array}$ \\
\hline $\begin{array}{l}\text { Population distribution } \\
\text { in Cairo districts }\end{array}$ & $\begin{array}{l}\text { Excel file containing the } \\
\text { population distribution } \\
\text { in Cairo districts according } \\
\text { to age }(<5 \text { and }>65)\end{array}$ & 2017 & (CAPMAS, 2017) \\
\hline Deprivation Index & $\begin{array}{l}\text { Deprivation index } \\
\text { table in Cairo districts }\end{array}$ & 2006 & (UNDP Egypt \& MOPLD [18]) \\
\hline
\end{tabular}

temperature [13]. Although there is a difference between LST and air temperatures, mitigating areas with high LST will reflect locations, which also have high air temperature [15]. Secondly, pertaining to the vulnerability, the demographic information of a place is needed, as neighbourhoods are categorized depending on social factors [13].

\subsection{Scope - study area, data, and period}

This study was carried out during summer season (June 2017) and focused on Cairo Governorate that consists of 46 districts. In the simulation, ArcMap version 10.2 was used to handle remote sensing visualization, manipulation and analysis of satellite images, and geographic data records. Also, Microsoft Excel was used in data processing and analyses. Description of the data is shown in Table 2 .

\subsection{Correlating NDVI and mean day-time LST in Cairo Governorate, Egypt}

In order to assess the exiting green coverage and heat related problem in Caro Governorate, Egypt, this part conducts a correlation between the NDVI and LST in Cairo. The main findings of this part will be presented and its results can be interpreted from Figure 5. First, the NDVI values in Cairo districts ranges from 0.08 to 0.25 , which indicates the lack of vegetation in all districts; as

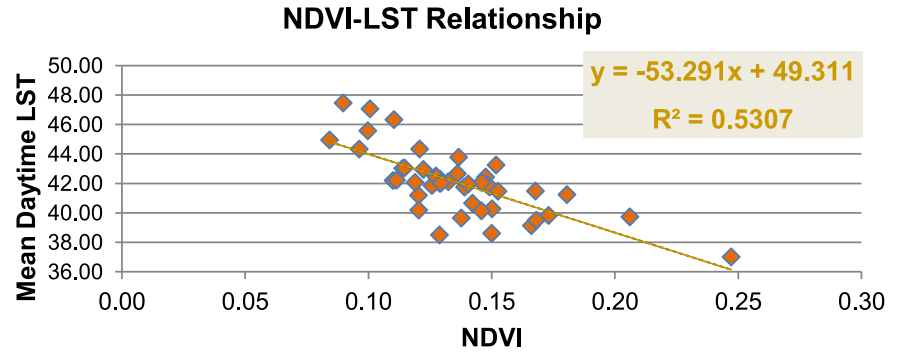

Fig. 5. NDVI and LST relationship in Cairo Governorate, Egypt. Source: (Author).

healthy vegetation's NDVI should be greater than 0.3. Second, some districts have very low NDVI, such as Tura and Badr districts, therefore, proposing UGC implementation in these districts will be a strategic technique for mitigating UHIE.

Furthermore, the relationship between the mean daytime LST and NDVI is investigated through correlation analysis and regression analysis. The coefficient of determination $\left(R^{2}\right)$ is a statistical method used to evaluate how well the regression line fits the actual data points. The analysis revealed that there is a significant inverse correlation between mean day-time LST and NDVI $\left(R^{2}=0.5307\right)$. Also, the value of $R$ is 0.73 which indicates a strong positive relationship; as $R$ values ranges from -1 to 1 . Finally, the correlation between the mean daytime LST and NDVI values reveals that well-maintained greenery (higher values of NDVI) exhibit lower LST value. 


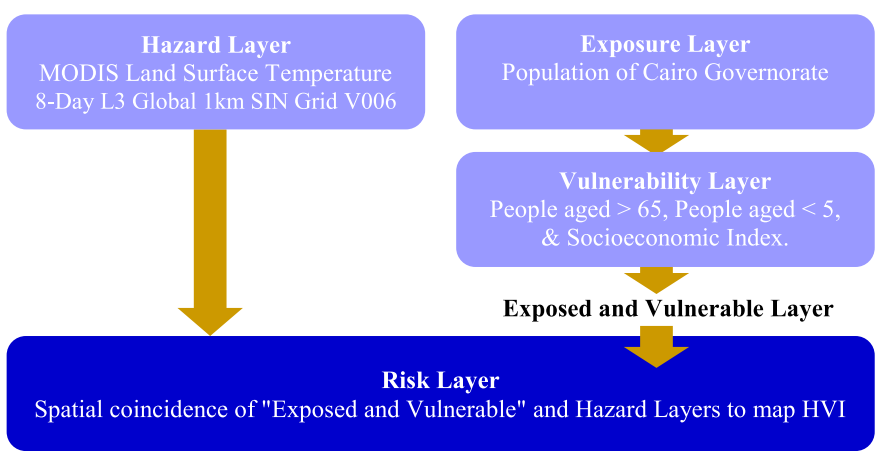

Fig. 6. Simplified workflow of the developed Geospatial Database to Map HVI. Source: Adopted and developed from [17].

\subsection{Prioritising districts on city scale level for UGC implementation}

Geospatial technologies, a new opportunity for an integrative system that can assist in hazards' mitigation, are used for mapping and prioritizing areas that have severe heat related impacts. It is important to note that the GIS system should have its inputs' data including urban characteristics, social vulnerabilities, and metrological information in order to derive trends and conclusions [14]. Recent research works attempt to develop Heat Vulnerability Index [16]. In these researches, the methodology adopted for assessing the risk is "Crichton's Risk Triangle" which was applied in many previous studies [14,17].

This risk definition is specifically adopted in this research work in order to simplify the process of building the GIS database, as it is mainly composed of layering system as the final risk layer is generated from the intersection of three determinants as shown in Figure 6 [17].

The hazard can be accounted by the increase in LST, which its exposure on the population can be determined according to the targeted vulnerable groups. A study conducted by Morabito et al. [14], took only the elderly as its vulnerability constrain, whereas that conducted by Norton et al. [13], took into account several vulnerability factors such as: the elderly and very young population and other affecting socioeconomic factors. Since it is possible to map different vulnerable items using Crichton's Risk Triangle [17], thus this research will take into consideration all the vulnerable factors as conducted by Norton et al. [13]. Thus, the aim of this section is to develop Heat-related Vulnerability Index (HVI) maps to determine the areas that need UGC intervention. The workflow of the developed geospatial database is shown in Figure 6.

\subsubsection{Hazard layer: day-time and night-time summer LST layers}

The day-time and night-time LST used in the study are based on NASA Satellite imagery, and to cover the study area, two raster images for LST were downloaded. These images were processed using GIS software "ArcMap 10.2". Finally, the LST values were extracted and scaled using equation (1), so that LST be displayed in Celsius.

$$
\begin{aligned}
& \text { MODIS_LST2017_Day }- \text { Time_Celsius } \\
& =[\text { Value }] * 0.02-273.15
\end{aligned}
$$

Then both day-time and night-time LST were normalized using equation (2), to have a standardized scale, which ranges between zero (low) and one (high) as shown in Figure 7.

$$
\beta=\frac{x-x_{\min }}{x_{\max }-x_{\min }}
$$

where $\beta$ corresponds to the normalized score, $x$ is the original value, while $x_{\max }$ and $x_{\min }$ are the maximum and minimum values across the complete data set.

\subsubsection{Exposure layer}

It consists of the population distributed in Cairo Governorate districts by age, obtained from Central Agency for Public Mobilization and Statistics (CAPMAS) according to 2017 census. The data is entered into ArcMap 10.2, and a table is generated, which is merged to the geographic features layer. This table contains deprivation index of districts based on a report by UNDP and MOPLD, 2006 [18].

\subsubsection{Vulnerability layers}

The vulnerability layer is made up of vulnerable types extracted from the exposure layer which includes: Number of People aged $>65$, Number of People aged $<5$, and Deprivation Index. All layers were normalized using equation (2) and graphically displayed as illustrated in Figure 8.

\subsubsection{Final risk layer}

To obtain the final risk layer (Fig. 10), the process followed by Tomlinson et al. [17] is implemented (Fig. 9), which involves the creation of an intermediate layer termed "Combined Exposed and Vulnerable", thus the three vulnerability layers were combined into a single layer (each weight of $33.3 \%$ ), then spatially combined with the hazard layer (each weight of 50\%) using equation (3).

$$
\begin{aligned}
& \text { [Exposure_and_vulnerability_Norm }] * 0.5 \\
& \quad+[\text { Norm_Mean_dayLST }] * 0.25 \\
& \quad+[\text { Norm_Mean_nightLST }] * 0.25
\end{aligned}
$$

\section{Results and discussions}

Results show that the NDVI values in Cairo districts ranges from 0.08 to 0.25 which indicate the lack of vegetation in almost all districts; as healthy vegetation's NDVI should be greater than 0.3. Furthermore, the correlation between the mean day-time LST and NDVI values reveals that well-maintained greenery (higher values of NDVI) exhibits lower LST value. In addition, the methodology adopted in this study yields a map depicting the HVI for the 46 districts in Cairo Governorate, Egypt. This HVI is divided into five categories: very high, high, moderate, low, and very low (Fig. 10). This 

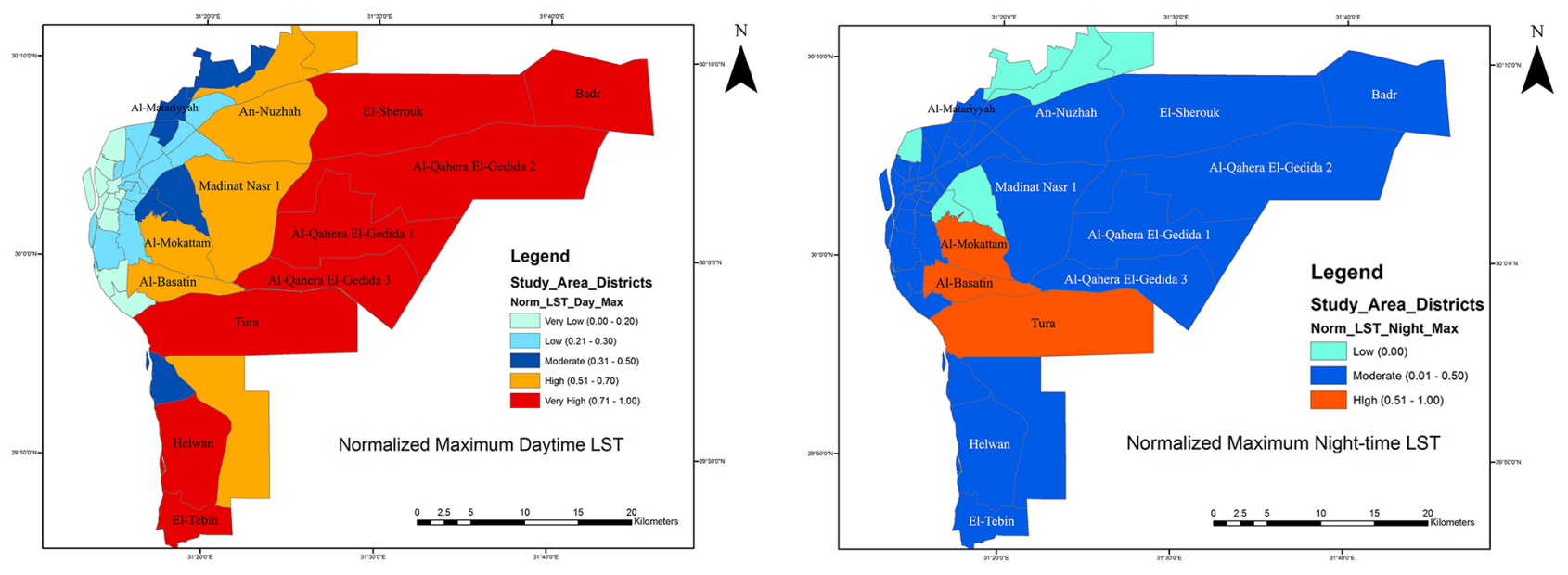

Fig. 7. Normalized maximum day-time LST (right) and night-time (left). Source: (Author).
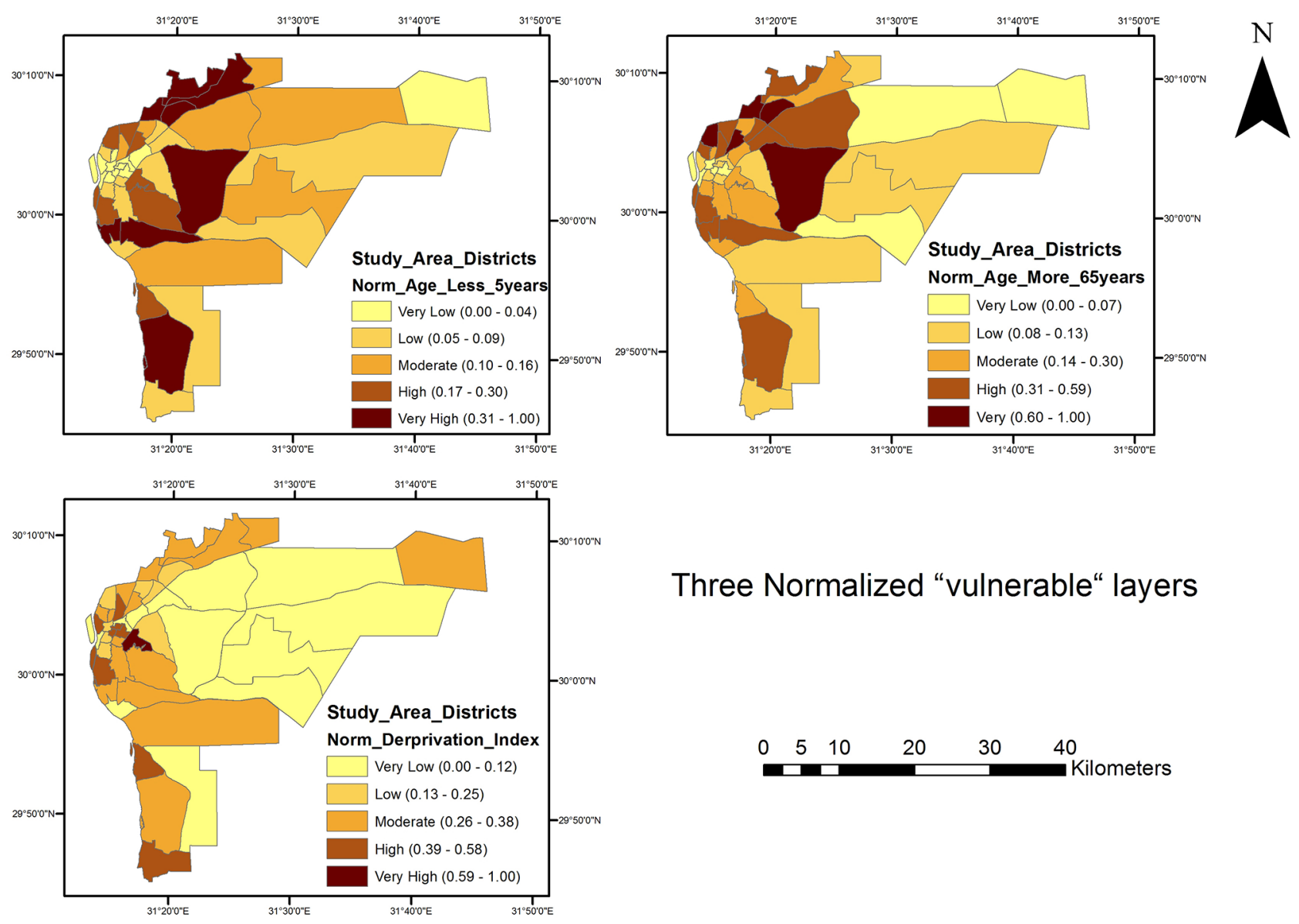

Three Normalized "vulnerable" layers

Fig. 8. Normalised vulnerability layers of Cairo Governorate districts. Source: (Author).

enables specialists to determine areas that crucially require UGC intervention. The highest risk is observed in five districts, namely: Al-Basatin (HDVI=1), Tura (0.97), Al-Mokattam (0.83), Helwan (0.8), and Madinat Naṣr-1 (0.78) as depicted in Figure 11.
Results show that the second category, high risk is present in 8 districts: Badr (0.69), El-Tebin (0.67), Al-Qahera El-Gedida 2 (0.66), Al-Qahera El-Gedida 1 (0.61), Al-Qahera El-Gedida 3 (0.58), An-Nuzhah (0.58), El-Sherouk (0.57), and Al-Matariyyah (0.56) as shown in Figure 11. 



Fig. 9. Framework to develop the final mapping of the Heat-related Vulnerability Index (HVI). Source: Adopted and developed from [17].

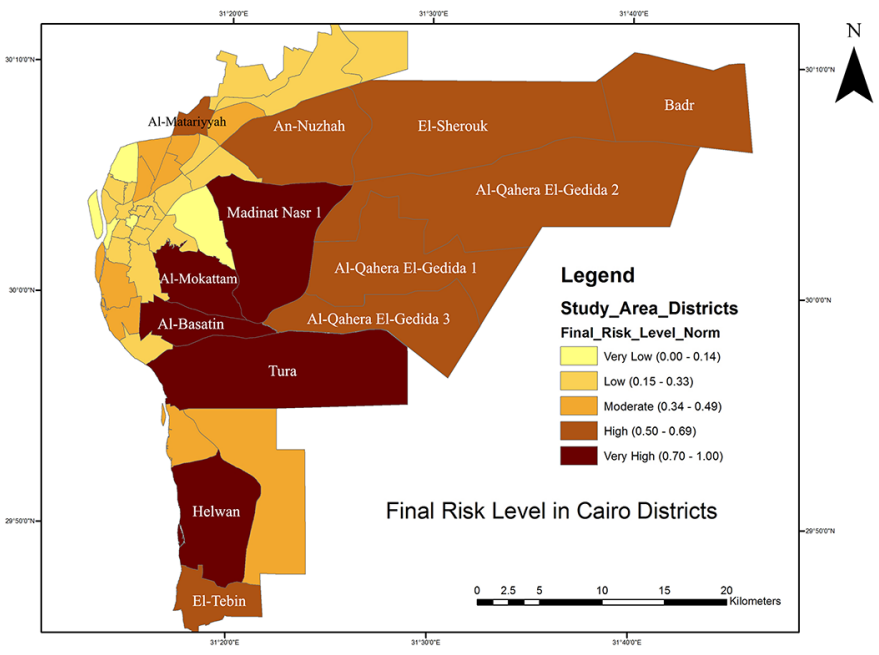

Fig. 10. Final risk layer in Cairo Governorate districts. Source: (Author).

The simulation results indicate that nine districts are at moderate risk and have HVI ranging from 0.34 to 0.49 . These districts are: Ain Shams, 15th of May, Al Masara, Al-Zawiyah Al-Hamra, Hadaiq Al-Qubbah, Dar Al Salaam, Mișr Al-Qadimah, Al-Sharabiyah, and Al-Amireya. It is clear from the HVI map that low risk districts have the HVI ranging from 0.15 to 0.30 . These 19 districts are: Al-Zeitoun (0.33), El Marg, Al-Khalifa, Al-Salam-1, Mișr al-Gedida, Shubra, Al-Jamaliyah, Bab Al-Shariyah, El-Darb al-Ahmar, Rud al-Faraj, Al-Waili, Al-Sayidah Zaynab, Manshiyat Naser, Al-Zahir, Al-Salam-2, Bulaq, Al-Maadi, Abdin, and Al-Azbakeya (0.17). In addition, only five districts have very low risk. These are Al-Muski, Al-Zamalik, Madinat Naṣr-2, Al-Sahel, and Qașr al-Nil.

Thus, as a first and urgent step, it is important to target areas at the 13 districts with very high risk and high risk, by proposing strategic UGC plans to assist in mitigating high temperatures, UHIE, and play a major role in enhancing the microclimate as well as adaptation to climate change risks. It is also vital to adopt and utilise the following guidelines when planning and implementing UGC in Cairo Governerate, and developing countries with similar conditions.

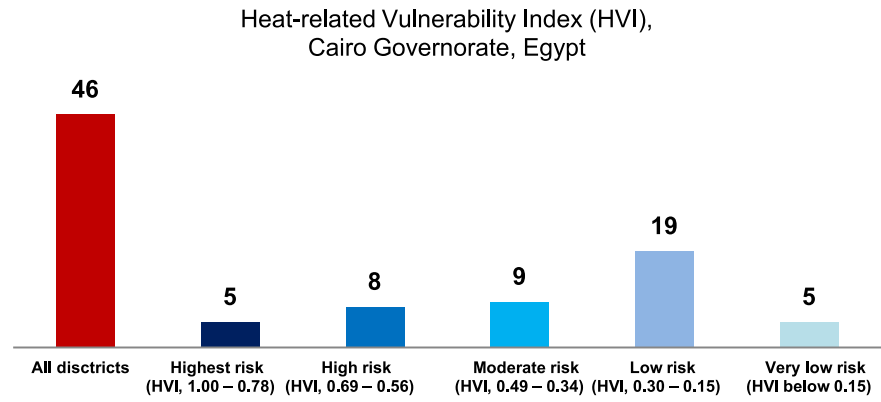

Fig. 11. Map of HVI distribution of the 46 districts in Cairo Governorate, Egypt. Source: (Author).

\subsection{Guidelines for UGC implementation in developing countries - Egypt}

This strategy is in line with the 2050 vision, which proposes an increase of the green area per capita in Greater Cairo Region (GCR) to reach $15.00 \mathrm{~m}^{2}$ [19]. It also attains to Egypt's vision 2030 and Sustainable Development Strategy, SDS 2030, mainly the energy and health environment sectors. The following are opportunities for incorporating new greenery:

(a) Implementing planned green areas that are not planted such as: areas localized for green belts, utilizing riverbanks as urban green corridor, and hillsides and plateaus greening;

(b) Utilizing areas that their land use has changed (such as: premises and sites of no longer use) or areas that its land use can change (such as: the gradual replacement of industrial areas, scattered areas with greenery, informal settlements, and deteriorated residential areas); and

(c) Doubling the use of spaces such as planting trees in car parking areas, cemeteries' areas, railway roads, streets, or airports landscape, etc. or vertical greening [20].

In addition, guidelines regarding sustainable vegetation planting include: planting regional native plants, adopting non-pollutant methods, and other techniques as shown in Figure 12. 

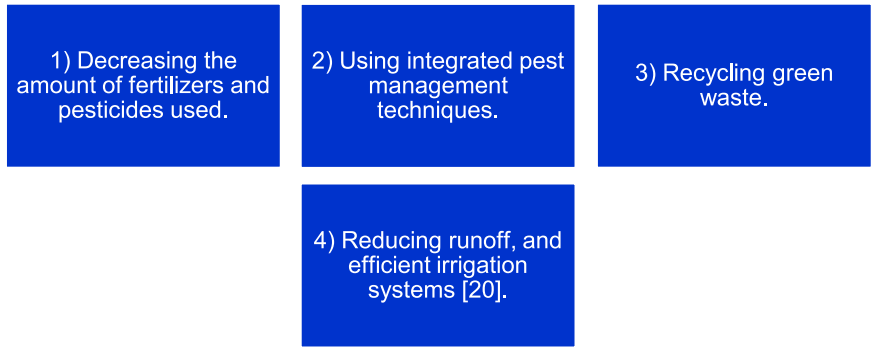

Fig. 12. Sustainable vegetation planting guidelines for mega cities in hot climate.

\section{Conclusions}

UHIE and UGC have been investigated using simulation programmes. Mapping the relationship between LST and the peoples' vulnerability is a method that can assist local governments to locate the hot spots that urgently require quick heat prevention and intervention. This study also achieved its goal by reviewing relevant literature on the UHIE and the cooling potential that can be provided by UGC in cities that are characterised with hot and dry summers. In addition, it proposed a framework for prioritising urban areas for UGC implementation. A tool to map the population vulnerability to extreme heat events in Cairo Governorate resulting from UHIE has been developed; it identifies high priority risk areas that should essentially receive intervention by applying more UGC as a significant action to mitigate UHIE in cities, reduce GHG emission, and assist in adapting to climate change risks. Moreover, guidelines for UGC application to mitigate UHIE in Cairo Governorate have been derived and established. It is important to note that implementing UGC will have a significant environmental impact, knowing that it does not only mitigate high temperatures, but it also reduces air pollution.

As indicated in the latest Health Organisation (WHO) report [21], air pollution is a major global concern, as it impacts human health severely and leads to about 7 million deaths annually worldwide, of which about 500000 in the MENA region, due to exposure from both outdoor and indoor pollutions. Therefore, implementing UGC extensively in cities, particularly in Cairo Governorate, a mega city, could lessen air pollution and other impacts and assist in reducing mortality rates from air pollution exposure. It is recommended that future research work on the development of UGC in developing countries such as Egypt should be on the street level.

\section{References}

1. T.R. Oke, The micrometeorology of the urban forest, R. Soc. 324, 335 (1989)
2. H. Taha, Urban climates and heat islands: albedo, evapotranspiration, and anthropogenic heat, Energy Build. 25, 99 (1997)

3. T.R. Oke, The energetic basis of the urban heat island, Q. J. R. Meteorol. Soc. 108, 1 (1982)

4. T.R. Oke, in Boundary Layer Climates, 2nd edn. (Methuen Co., London, New York, 1987), p. 435

5. M. Kolokotroni, I. Giannitsaris, R. Watkins, The effect of the London urban heat island on building summer cooling demand and night ventilation strategies, Sol. Energy 80, 383 (2006)

6. M.A. Lokoshchenko, Urban climate urban "heat island" in Moscow, Urban Clim. 10, 550 (2014)

7. K. Abutaleb, A. Ngie, A. Darwish, M. Ahmed, S. Arafat, F. Ahmed, Assessment of urban heat island using remotely sensed imagery over greater Cairo, Egypt, Adv. Remote Sens. 4, 35 (2015)

8. H.A. Effat, O.A.K. Hassan, Change detection of urban heat islands and some related parameters using multi-temporal Landsat images; a case study for Cairo city, Egypt, Urban Clim. 10, 171 (2014)

9. I.A. El-magd, A. Ismail, N. Zanaty, Spatial variability of urban heat islands in Cairo City, Egypt using time series of Landsat Satellite images, Int. J. Adv. Remote Sens. GIS 5, 1618 (2016)

10. A. Raymond, Cairo (Harvard University Press, Cambridge, MA, 2000)

11. A.M. El-Zafarany, Existing Green Areas in Cairo: Comparison with Planning Criteria and International Norms, Cairo, Egypt (2004). http://www.egyptarch.net/research/cairour bandesert.pdf (accessed June 27, 2018)

12. N. Kafafy, Y. Al-betawi, Urban Green Space Benefits and the Pivotal Role of Conservation, Cairo's Case - Egypt, 1-13. https://core.ac.uk/download/pdf/19396743.pdf (accessed June 28, 2018)

13. B.A. Norton, A.M. Coutts, S.J. Livesley, R.J. Harris, A.M. Hunter, N.S.G. Williams, Planning for cooler cities: a framework to prioritise green infrastructure to mitigate high temperatures in urban landscapes, Landsc. Urban Plan. 134, 127 (2015)

14. M. Morabito, A. Crisci, B. Gioli, G. Gualtieri, P. Toscano, V. Di Stefano et al., Urban-hazard risk analysis: mapping of heat-related risks in the elderly in major Italian cities, PLoS One 10, e0127277 (2015)

15. A. Matzarakis, F. Rutz, H. Mayer, Modelling radiation fluxes in simple and complex environments - application of the RayMan model, Int. J. Biometeorol. 51, 323 (2007)

16. L. Inostroza, M. Palme, F. De La Barrera, A heat vulnerability index: spatial patterns of exposure, sensitivity and adaptive capacity for Santiago de Chile, PLoS One 11, e0162464 (2016)

17. C.J. Tomlinson, L. Chapman, J.E. Thornes, C.J. Baker, Including the urban heat island in spatial heat health risk assessment strategies: a case study for Birmingham, UK, Int. J. Health Geogr. 10, 42 (2011)

18. UNDP Egypt and MOPLD, Taqareer al-Tanmia Al-basharia li-l-muhafazat Al-Masria: Taqreer Al-Qahira, UNDP, Cairo, (Human Development Reports for Egyptian governorates: Cairo's Report), 2006

19. General Office of Physical Planning - GOPP, Cairo Future Vision 2050: Within a National Vision of Egypt [PowerPoint presentation], Cairo, Egypt (2009). https://cairofrombelow. 
files.wordpress.com/2011/08/cairo-2050-vision-v-2009-gopp12-mb.pdf (accessed July 1, 2018)

20. A.M. El-Zafarany, Green Areas in Greater Cairo: The Problem and Solution Opportunities. Cairo, Egypt (2004). http://www.egyptarch.net/research/cairogreanstrategies. pdf (accessed July 1, 2018)

21. World Health Organisation (WHO) (2017). http://www. who.int/airpollution/en/ (accessed July 2, 2018)

Cite this article as: Mohsen Aboulnaga, Mona Mostafa, Mitigating heat islands effect in mega cities through districts' prioritisation for urban green coverage applications: Cairo - Egypt as a case study, Renew. Energy Environ. Sustain. 4, 5 (2019) 